\title{
Congenital anal anomalies in two families with the Opitz G syndrome
}

\author{
JOHN L TOLMIE*, NORMAN COUTTS $\dagger$, AND IAN K DRAINER \\ From *The Duncan Guthrie Institute of Medical Genetics, and $\ddagger$ the Department of Paediatric Surgery, Royal \\ Hospital for Sick Children, Yorkhill, Glasgow G3 8SJ; and the Department of Paediatrics, Hawkhead \\ Hospital, Paisley PA2 7DU.
}

SUMMARY Five children from two families presented to a regional neonatal surgical unit between 1959 and 1984 with congenital anal anomalies and other malformations resulting from an autosomal dominant inherited condition, the Opitz $G$ syndrome. This and other Mendelian $\stackrel{\oplus}{+}$ causes of congenital anal malformations are briefly discussed in view of their importance for:genetic counselling.

The frequency of imperforate anus among the newborn of North America in one study was 2.4 per 10000 births. $^{1}$ In $42 \%$ of these cases the anomaly was isolated and in the remainder it occurred in association with other malformations. Cases with isolated imperforate anus are usually sporadic and the empiric recurrence risk is less than $1 \%,{ }^{2}$ but there are reports of familial cases of isolated anal anomalies (McKusick ${ }^{3}$ Catalogue Nos 10710, 20750, 30180). Imperforate anus with other malformations has several possible causes, including chromosome imbalance, single gene defects, various teratogens, and unknown factors. ${ }^{4}$ Single gene defects are important in view of the high recurrence risk, but as they are rare and often variable in presentation, the diagnosis may be overlooked. In this report we describe two families in which a rare autosomal dominant congenital malformation syndrome, the Opitz G syndrome, was present. Over a period of 25 years five subjects from these two families presented in the newborn period to a regional paediatric surgical unit with malformations which required surgical treatment.

\section{Case reports}

FAMILY 1

The pedigree is shown in fig 1 . The proband (IV.2) was the second child of unrelated Scottish parents. He was born in 1984 at 36 weeks' gestation by elective Caesarean section for polyhydramnios and raised maternal blood pressure. The birth weight

Received for publication 12 August 1986. Revised version accepted for publication 13 October 1986.
$(2.36 \mathrm{~kg})$ was on the 10 th centile, while the heacto circumference $(\mathrm{OFC} 33 \mathrm{~cm})$ and the length $(48 \mathrm{~cm})$ were close to the 50th centile. He had an imperfo 3 rate anus which was treated by anoplasty, hyper. telorism, a high arched palate, and positional talipes -

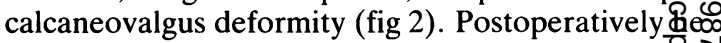
had frequent cyanotic attacks and was unable $40-$ swallow his secretions. All subsequent attemptsoi oral feeding resulted in choking and aspiration. fluid into the lungs. Repeated barium studies showed pharyngeal incoordination with regurgita tion into the nasopharynx and aspiration into the trachea. He remained in hospital from birth and needed to be entirely tube fed during the first year occasionally requiring nasopharyngeal suction when secretions were excessive. At one year of age hiș. length, weight, and OFC were just below the 10th centile. He had hypertelorism and significant deङ velopmental delay with overall function estimated tó

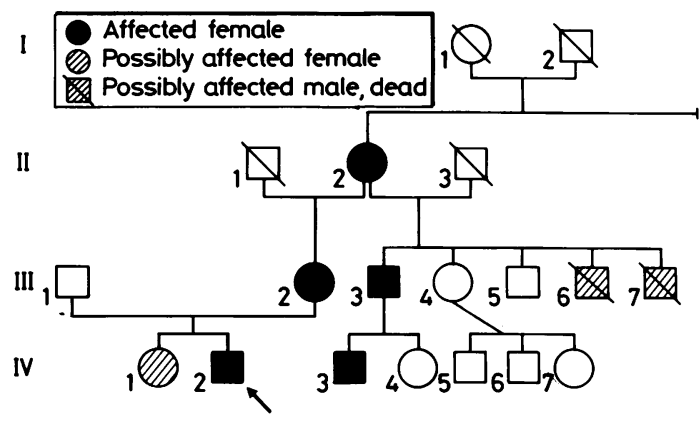

FIG 1 Pedigree of family 1. 


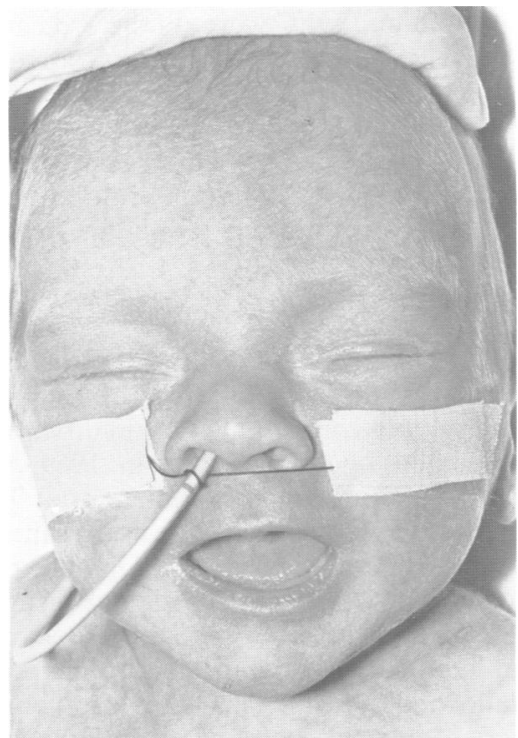

FIG 2 The proband, family 1. Note hypertelorism and the feeding tube.

be at an eight month level. Chromosome analysis showed a normal 46,XY male karyotype. At 14 months of age the proband was found apnoeic in his cot at home and attempts at resuscitation were unsuccessful. Full necropsy revealed no internal malformations or evidence of aspiration, but there were mild inflammatory changes in the bronchi.

The proband's mother had no history of swallowing problems, hoarseness, or constipation. She attended a normal school but required some remedial teaching. Her only physical signs were hypertelorism (inner canthal, outer canthal, and interpupillary distances were above the 90th centile) and an anteriorly placed anus. The proband's sister also has hypertelorism but is otherwise normal. Two half sibs of the proband's mother (III.6 and III.7) were reported to have died in the newborn period after undergoing surgery for imperforate anus, but hospital records could not be traced to verify this. Another relative of the proband (III.3) had congenital anal stenosis treated by an anal stretch procedure at six weeks of age in 1959 . He also had hypertelorism and glandular hypospadias (fig 3); he attended a normal school and is employed as a non-skilled manual worker. This man's son (IV.3) was born with hypertelorism and a low type of imperforate anus which was repaired by anoplasty. He subsequently had recurrent choking and cyanotic attacks on attempting oral feeds which resolved by six weeks of age. At five years, his height was on the 25th centile and development within normal limits; his only abnormal physical sign is hypertelorism.

FAMILY 2

The two affected boys were half sibs born of the same mother but with different fathers. The elder presented at birth in 1961 with hypertelorism, a cleft lip and alveolar margin, an umbilical hernia, and glandular hypospadias (fig 4). He had initial feeding

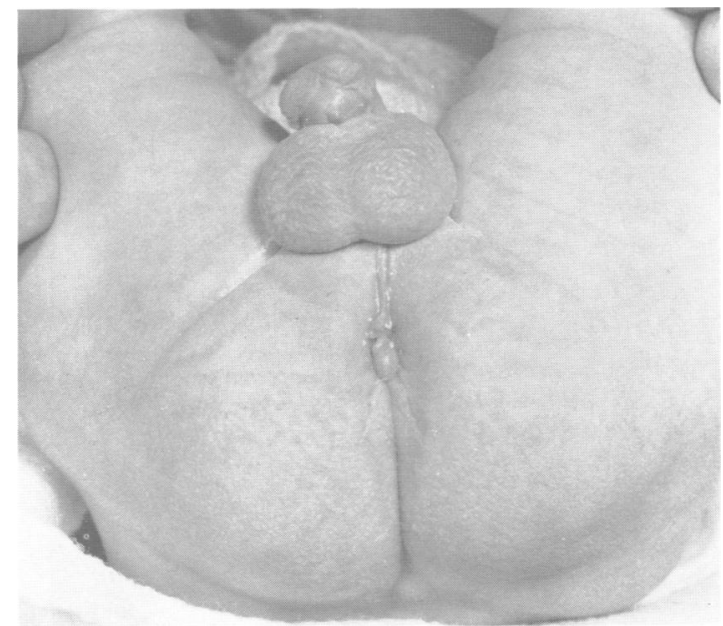

FIG 3 Congenital anal stenosis (note the perianal skin tag) and hypospadias in III.3, family 1.

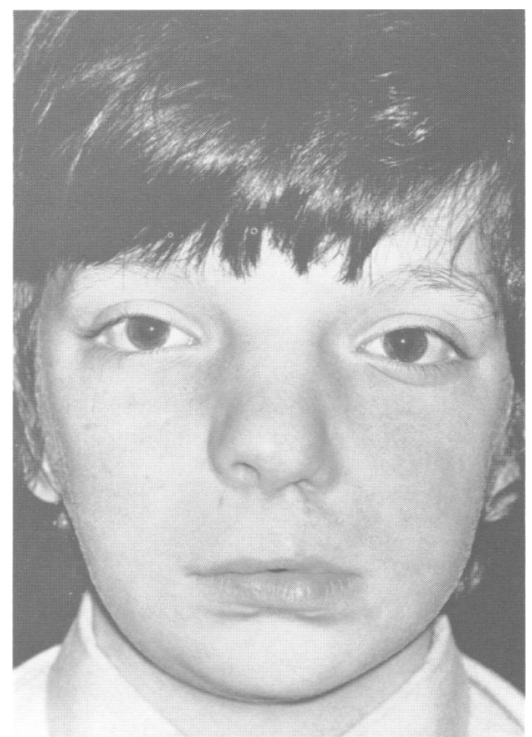

FIG 4 The first born affected boy in family 2. Note hypertelorism and repaired cleft lip. 
difficulties but these resolved after repair of the cleft at three months. Subsequent development has been entirely normal. His half brother, born in 1983, had hypertelorism, posteriorly rotated ears, an umbilical hernia, and hypospadias (fig 5). He also had a low type of imperforate anus and a cardiac murmur thought to indicate a small VSD. In infancy he was described as a sickly baby and tended to vomit after most feeds. He sat at nine months, walked at 16 months, and knew six words at 18 months. At this
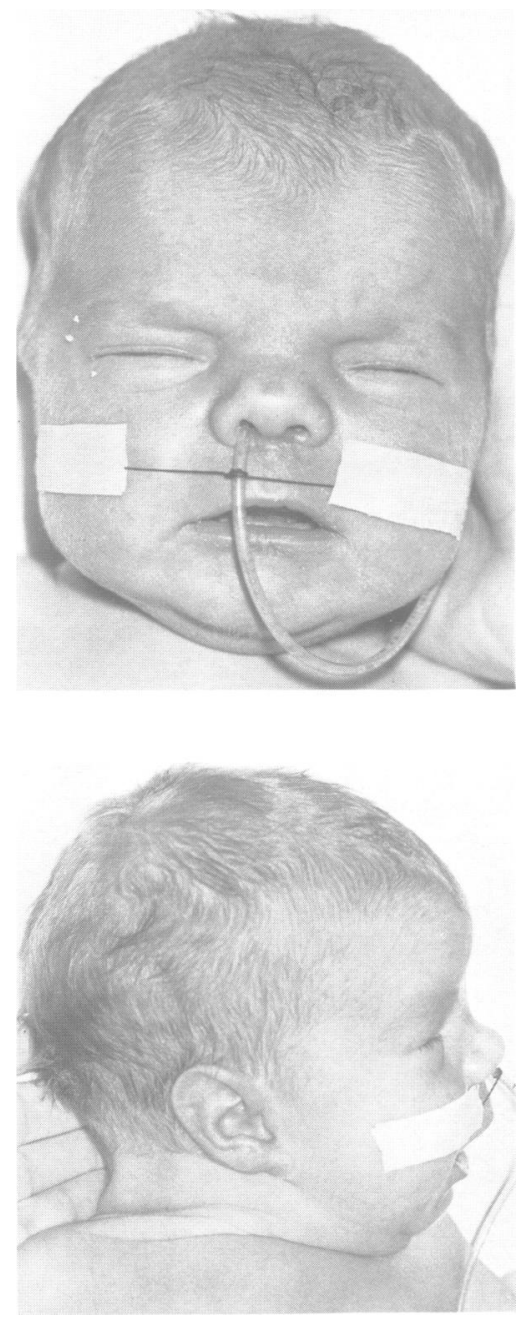

Fig 5 Second born affected boy in family 2. Note hypertelorism, posteriorly rotated ears, and the feeding tube. age his weight and OFC were on the 3 rd centile anc his height on the 10th centile. Chromosome analysis showed a normal 46,XY male karyotype.

The mother of both boys gave no history of feeding difficulties in infancy or of constipation. She is of normal intelligence and does not have hyperte $\overline{\bar{n}}$ lorism. There was no other family history of note.

\section{Discussion}

The features described in each of these families are consistent with the diagnosis of the $G$ syndrome $\vec{\omega}$ This is a multiple congenital abnormality syndromes first delineated by Opitz et al in 1969, which i⿸厃㔾्ठ inherited as an autosomal dominant trait. ${ }^{6-8}$ Males are generally more severely affected than females $\stackrel{+}{-}$ This is supported by the presentation of our families and the occurrence of male to male transmission iro family 1 . On the basis of over 30 published cases, the cardinal features are hypertelorism, hypospadias? and swallowing defects. This latter problem may be due to oesophageal incoordination or a laryngeab cleft. Less common features are clefts of the lip and palate, abnormal bifurcation of the trachea $\frac{3}{0}$

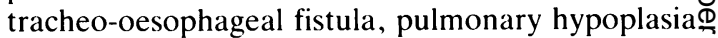
imperforate anus, and cardiac and renal defects $\overrightarrow{0}$ Mild mental retardation is a variable featugepo Occasionally the more serious abnormalities case death in the neonatal period. In general, midlise structures are particularly vulnerable to malformas tion and an affected subject may have any combinae tion of malformations or, like the mother of thळ affected boys in family 2 , apparently none at all $\mathbb{Q}$ Gynaecological and radiological examination of apparently asymptomatic females at risk of carrying the gene may rarely reveal occult genital, tracheo? bronchial, or pulmonary anomalies which indicate an affected subject. ${ }^{7}$

There is an excess of stillbirths and miscarriages i i⿳⺈⿴囗十 families with the $\mathrm{G}$ syndrome. Polyhydramnios wa的 noted before delivery of the proband in family 1 ?. this was probably due to defective fetal swallowingo Another rare in utero manifestation of the $\mathcal{G}$ syndrome is non-immune fetal hydrops and this was successfully treated in one case by thoracocentesis and intravenous transfusion of albumin carried ou黑. at fetoscopy."

Several other syndromes may have an anorecta malformation as one feature (table). Some of thesE conditions carry a high recurrence risk and ard recognised by their striking associated featureso while other syndromes, based on a few reported cases, are incompletely delineated. Our experience्ह with these two families underlines the importance of obtaining an extended pedigree while being alert to the possibility of variable expression of a single gen $\overrightarrow{\vec{P}}$ 
TABLE Syndromes which may include an anal malformation.

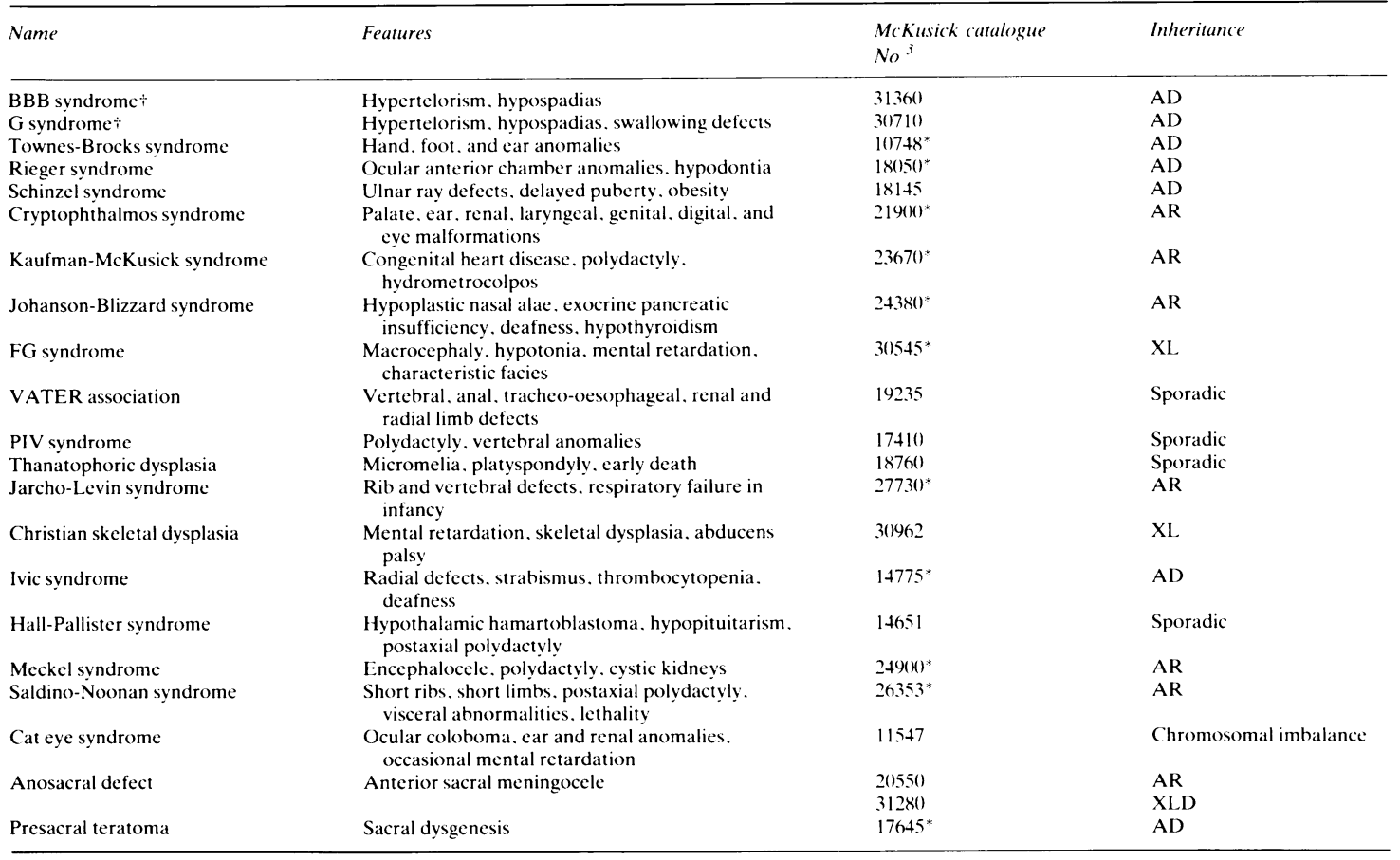

* Mode of inheritance accepted by McKusick.

$\rightarrow$ Although listed in the sex linked catalogue, autosomal dominant inheritance is now accepted

AD, AR, XL: autosomal dominant, autosomal recessive, $\mathrm{X}$ linked inheritance.

defect as a cause of congenital malformations in second and third degree relatives.

We thank Dr John M Opitz for his helpful comments on the above cases, the Department of Medical Illustration, The Royal Hospital for Sick Children, Glasgow, for preparing the illustrations, and Miss Elaine Robertson for typing the manuscript.

\section{References}

' Myrianthopoulos NC. Chung CS. Congenital malformations in singletons: epidemiologic survey. Birth Defects 1974:X:1-58.

2 Stephens FD, Smith ED. Ano-rectal malformations in children. Chicago: Year Book Medical Publishers, 1971:170-1.

${ }^{3}$ McKusick VA. Mendelian inheritance in man. 6th ed. Baltimore: Johns Hopkins University Press, 1983.
- Pinsky L. I he syndromology of anorectal malformation (atresia. stenosis. ectopia). Am J Med Genet 1978:1:461-74.

5 Opitz JM. Frias JL. Gutenberger JE. Pellett JR. The (j syndrome of multiple congenital anomalies. Birth Defects 1969:V(2):95-101.

"Little JR. Opitz JM. The G syndrome. Am J Dis Child 1971:121:505-7.

${ }^{7}$ Funderburk SJ. Stewart R. The G and BBB syndromes: case presentations, genetics and nosology. Am J Med Genet 1978:2:131-44

"Farndon PA. Donnai D. Male to male transmission of the $G$ syndrome. Clin Genet 1983:24:446-8.

"Patton MA. Baraitser M. Nickolaides K. Rodeck CH. Gamsu H. Prenatal treatment of fetal hydrops associated with the hypertelorism-dysphagia syndrome (Opitz G syndrome). Prenatal Diagnosis 1986:6: 109-15.

Correspondence and requests for reprints to $\mathrm{Dr} \mathrm{J} \mathrm{L}$ Tolmie, Duncan Guthrie Institute of Medical Genetics, Yorkhill Hospitals, Glasgow G3 8SJ. 